\title{
Arquitetura e Urbanismo, saber/fazer transdisciplinar?
}

\author{
Alison Jorge Alves do Carmo, \\ Maria de Jesus de Britto Leite*
}

\begin{abstract}
Resumo $\mathrm{O}$ artigo defende a transdisciplinaridade como inerente à arquitetura e urbanismo. São apresentadas revisitações históricas à teoria da disciplina e aportes teóricos que denotam uma relação comum com demais campos do conhecimento e do trabalho humano. Em especial, parte-se da teoria de Françoise Choay para se sugerir o ofuscamento dessa transdisciplinaridade por uma objetivação teórico-espacial ocorrida na Era Moderna. Mas transdisciplinaridade que hoje estaria sendo resgatada pela ideia de "Campo Ampliado". Essa discussão é ilustrada com críticas à recente apropriação do transdisciplinar conceito de Autopoiese pelo arquiteto Patrik Schumacher, que desenvolve, não obstante, uma sistematização teórica com tendências disciplinares unilaterais. E para estas análises, contribuem excertos oriundos das Ciências da Complexidade, onde encontra-se o conceito de Autopoiese, e da Fenomenologia.
\end{abstract}

Palavras-chave: teoria e história da arquitetura e urbanismo, complexidade, espaço.

\section{Arquitectura y Urbanismo, ¿conocer/hacer transdisciplinario?}

Resumen El artículo defiende la transdisciplinariedad como inherente a la arquitectura y el urbanismo. Se presentan revisiones históricas a la teoría de la disciplina y aportes teóricos que demuestran una relación común con otros campos del conocimiento y del trabajo humano. En particular, se basa en la teoría de Françoise Choay para sugerir la ofuscación de esta transdisciplinariedad por una objetivación teórico-espacial ocurrida en la Era Moderna. Pero transdisciplinariedad que hoy sería rescatada por la idea de "Campo Expandido". Esta discusión se ilustra con críticas a la reciente apropiación del concepto transdisciplinario de Autopoiesis por parte del arquitecto Patrik Schumacher, quien desarrolla, sin embargo, una sistematización teórica con tendencias disciplinarias unilaterales. Y para estos análisis, están tomados extractos de las Ciencias de la Complejidad, donde se encuentran el concepto de Autopoiesis, y de la Fenomenología.

Palabras clave: teoría y historia de la arquitectura y urbanismo, complejidad, espacio.

\section{Architecture and Urbanism, transdisciplinary knowledge/work?}

Abstract The article defends the transdisciplinarity as inherent
to architecture and urbanism. There are presented historical
revisits to the theory of discipline and theoretical contributions
that demonstrate a common relationship with other fields
of knowledge and human work. In particular, it's based on
the theory of Françoise Choay to suggest the obfuscation of
this transdisciplinarity by a theoretical-spatial objectification
occurred in the Modern Era. But transdisciplinarity that today is
being rescued by the idea of "Expanded Field". This discussion
is illustrated with criticisms to the recent appropriation of
the transdisciplinary concept of Autopoiesis by the architect
Patrik Schumacher, who develops, nevertheless, a theoretical
systematization with unilateral disciplinary tendencies. And for
these analyzes, excerpts are taken from Sciences of Complexity,
where is the concept of Autopoiesis, and from Phenomenology.

Keywords: theory and history of architecture and urbanism, complexity, space. 
E ste artigo discute a transdisciplinaridade como qualidade própria da arquitetura e urbanismo. São apresentadas bases teóricas e revisitações históricas a partir das quais se evidencia a-esse campo como um saber teórico e prático que se liga de modo total ao conhecimento e ao know-how humano. Comenta-se centralmente a recente ideia de "campo ampliado" inserida na arquitetura e urbanismo, a partir principalmente das Ciências da Complexidade e, em especial, do conceito de Autopoiese. Estes se mostram como instrumentos potencialmente úteis para uma abordagem da transdisciplinaridade do espaço construído sob perspectivas contemporâneas. E não só isso. Também a apropriação do conceito Autopoiese na arquitetura e urbanismo se mostra como objeto de investigação crítica no tocante à transdisciplinaridade. Criado na última década de 70 pelos cientistas chilenos Humberto Maturana e Francisco Varela, o conceito teve sua primeira apropriação na arquitetura e urbanismo a partir do arquiteto Patrik Schumacher, sócio do Zaha Hadid Architects. Em sua obra "The Autopoiesis of Architecture", composta de dois extensos volumes, Schumacher (2011, 2012) desenvolve uma teoria dita "autodescritiva" para a arquitetura e urbanismo, mas que parece ir na contramão da transdisciplinaridade aqui sugerida, bem como da própria ideia de Autopoiese e outras teorias da complexidade. Especificamente, ele defende a vanguarda contemporânea para a técnica digital de projeto do parametricismo - instrumento familiar à sua experiência profissional - e realiza uma sistematização teórica segundo a qual "a arquitetura não mais tolera que um portador da reputação de arquiteto tenha qualquer outra ambição externa" ". Mas, não obstante afirmações como essa, a ideia de Autopoiese envolve diferentes áreas do conhecimento, como a biologia, a neurociência, a epistemologia e a sociologia, posto que se trata de um conceito que busca fundir o "saber" e o "fazer" em um só entendimento. Ademais, pensadores recentes como o brasileiro Humberto Mariotti (1999) e o austríaco Fritjof Capra (1996) dele se apropriam em discussões ainda mais alargadas, como a respeito da cultura e da sustentabilidade.

Ao investigar essa apropriação da ideia Autopoiese na teoria da arquitetura e urbanismo, indagamos, através de uma análise crítica, se este seria um saber/fazer transdisciplinar. Como ponto de partida, o artigo apresenta uma breve explanação sobre discussões recentes em transdisciplinaridade. Depois, são revisitados momentos históricos da

* Alison Jorge Alves do Carmo é Arquiteto e Urbanista, Doutorando na Pós-Graduação em Desenvolvimento Urbano da Universidade Federal de Pernambuco, ORCID <https://orcid.org/00000002-3543-9027>. Maria de Jesus de Britto Leite é Arquiteta e Urbanista, Professora na graduação de Arquitetura e Urbanismo e na Pós-Graduação em Desenvolvimento Urbano da Universidade Federal de Pernambuco (MDU-UFPE), ORCID <https://orcid. org/0000-0002-3284-1280>. teoria da arquitetura e urbanismo desde a Antiguidade até a Contemporaneidade, reconhecendo-se aí ligações com áreas do conhecimento e do trabalho humano os mais diversos, e erguendo-se então interrogações às premissas de Schumacher, cuja proposta teórica e entendimento de Autopoiese são comentados em seguida. E por fim, são apresentados outros aportes teóricos que reforçam a arquitetura e o urbanismo como disciplinas transdisciplinares.

O principal desses aportes teóricos provém da historiadora francesa Fraçoise Choay, de seus livros "O Urbanismo" (2015) e "A Regra e O Modelo" (2010). Nesse conjunto literário, Choay faz uma contundente crítica às ascendências científicas da arquitetura e urbanismo. Ela atenta para a ocorrência de um cientificismo e de uma objetivação 
1 "Architecture no longer tolerates that the bearer of architectural reputation has any outside ambitions." (SCHUMACHER, 2012, p.410).

2 "O que se costuma designar ciência da complexidade ou teorias da complexidade é um conjunto de teorias e subteorias inter-relacionadas que vêm se consolidando a partir dos anos 1960 e 70, e que ainda estão em pleno desenvolvimento. Entre estas estão a teoria do caos, as várias teorias vinculadas à auto-organização, e outras, como a dos fractais. Na verdade, não há ainda no meio científico e no de sua divulgação uma posição consensual sobre as definiçôes e nomenclaturas para esse corpo teórico. Podemos começar dizendo que ciência da complexidade é a ciência que trata dos sistemas dinâmicos denominados caóticos e de seus processos de transformação. " (GRILLO, 2008, p.128-129). teórico-espacial ao longo da modernidade e que teriam acarretado graves consequências para as teorias e a construção do Espaço, estando ainda supostamente ligados a diversas problemáticas urbanas modernas. Tais ocorrências, como as interpretamos, teriam ofuscado a transdisciplinaridade da arquitetura e urbanismo, uma qualidade supostamente inata que, não por acaso, estaria sendo resgatada na contemporaneidade pela ideia de "campo ampliado" oriunda das artes, mas inserida em 2004 no espaço construído através do arquiteto Anthony Vidler (2013).

Outro aporte teórico adotado foi o das já citadas Ciências da Complexidade², âmbito filosófico-científico em que se encontra o conceito de Autopoiese e também outros conhecimentos e práticas ligados à ideia de "campo ampliado". Esse aporte aufere não só maiores entendimentos sobre a ideia de Autopoiese, mas também contribuições teóricas para a investigação da arquitetura e urbanismo como um campo transdisciplinar.

Finalmente, não há como refletir sobre a arquitetura e o urbanismo enquanto disciplinas transdisciplinares sem confrontar essa discussão com aquela da Estética, a respeito da autonomia da Arte. Afinal, para além de sua condição humanista, técnica, social, há na arquitetura a condição de arte, parecendo-nos que podem vir daí influências ao intuito de Schumacher de considerá-la como independente, e buscando na Autopoiese um apoio científico para o seu argumento. Assim, nos colocamos ainda o seguinte argumento: a transdisciplinaridade - entendida inicialmente como ampliação dos campos do conhecimento em uma busca transversal a variadas disciplinas - não é oposta ao que se denomina "autonomia" no campo das artes. Isso porque a autonomia na Arte se refere ao modo de expressar de uma arte, não ao processo de conhecer desta mesma arte. É o que ocorre na teoria da arquitetura e urbanismo se nos voltamos ao que propunha o filósofo Evaldo Coutinho (1970), ao afirmar que a autonomia da arquitetura se dá em função de sua matéria primeira - o Espaço. De modo paralelo, a matéria primeira da pintura seria a tela, da música, o som, do cinema, a imagem... Daí que também fazemos aqui uma pequena incursão no modo como o Espaço se expressa segundo o arquiteto Norberg-Schulz. A teoria desse autor revela contribuições da fenomenologia ao campo ampliado da arquitetura ao tentar abarcar o pensar e o fazer - de modo semelhante ao que propõe a ideia de Autopoiese no âmbito científico - no exercício de se perceber a transdisciplinaridade do Espaço, isto é, da arquitetura e urbanismo.

\section{Algumas primeiras palavras sobre transdisciplinaridade}

A discussão sobre transdisciplinaridade não é nova, e sua inserção no campo da arquitetura e urbanismo acompanha o seu desenvolvimento e história. De modo central, questionamentos sobre a interação entre diferentes campos do conhecimento têm sido uma constante desde que, a partir da idade média, e posteriormente intensificado na modernidade, a distinção entre diferentes saberes tornou-se esteio do pensamento científico, analítico. Esse, um modo de pensar surgido em reação ao predomínio teológico medieval que concatenava toda a razão humana, e que ao dele se apartar, sempre manteve em vista outras considerações sobre a unidade do conhecimento. Pois para se aplicar as muitas análises que a realidade sempre demandou, por ser complexa, tornava-se necessária uma razão integradora que gerasse 
o diálogo entre o conhecimento e a práxis. Desde então, e ainda hoje, a estruturação do conhecimento ocidental tem conservado a Universidade como instituição congregadora de diferentes escolas e faculdades que preservam e transmitem as bases de cada campo do saber e do fazer. Uma herança advinda da antiguidade e que perpassa a própria idade média, como que a expressar um interesse natural do homem pela unidade, pela universalidade.

Foi somente no séc. XX que questões ligadas à unidade do conhecimento ganharam o termo "transdisciplinaridade". Talvez porque motivadas, desde finais do séc. XIX, por novas teorias científicas que colocaram em xeque muitas das bases do pensamento moderno, desde a relatividade de Einstein à física quântica de Heisenberg por exemplo, a questionar o absolutismo das ideias de tempo, espaço, matéria e energia (SANTOS, 2008). E também em razão das muitas crises acumuladas pelo séc. $X X$, que passaram a demandar novos modelos multidimensionais para o desenvolvimento humano. Desde então, a segmentação disciplinar da ciência passou a ser cada vez mais questionada, gerando o surgimento de novas propostas e termos que buscam integrar diferentes conhecimentos, como "multidisciplinaridade", "interdisciplinaridade" e a própria "transdisciplinaridade". Thierry Ramadier (2004) remete a 1973 a criação do primeiro centro transdisciplinar na França, como resultado das discussões e produções teóricas de autores como Bohr, Piaget e Friedmann. Um quadro que também se completa com propostas teóricas adjacentes e inéditas à época, como o Pensamento Sistêmico de Ludwing von Bertalanffy e o próprio Pensamento Complexo, encabeçado por Edgar Morin. Cada vez mais, os esforços têm sido o de lapidar o conhecimento na construção de um saber capaz de dialogar com a realidade e que não se limite aos preceitos científicos modernos.

Lacerda (2013) nos esclarece que "multidisciplinaridade" diz respeito ao estudo de um mesmo objeto por diferentes campos do conhecimento; "interdisciplinaridade", ao intercâmbio e transferência de métodos entre os distintos saberes na elaboração de suas análises; e "transdisciplinaridade", finalmente, à construção comum do saber, colocado acima dos limites disciplinares. Além disso, Ramadier (2004) salienta que nenhum desses termos se contrapõe à ideia de disciplinaridade, e sequer Ihe são opostos. Ao contrário, eles se complementam, dado que a unidade do conhecimento não seria algo indivisível, um processo, mas um estado, no sentido de "condição". Segundo este autor, a transdisciplinaridade emerge de uma conotação mais sistêmica do que totalizante, estando ligada à ideia de uma articulação entre saberes para criar uma melhor compreensão do "todo" pelo entendimento de suas camadas.

Foi também na segunda metade do séc. XX que as discussões sobre transdisciplinaridade incidiram na arquitetura e urbanismo. Do modernismo à contemporaneidade, a teoria e a prática do espaço construído passaram a lidar mais diretamente com uma série de questões econômicas, sociais, políticas e até epistemológicas que, principalmente com o pós-modernismo, puseram-se a explorar formas de se analisar e conceber o Espaço de modo mais adequado e contextualizado a diferentes lugares, culturas, ambientes e histórias. Mas um processo que apenas parece ter retomado uma histórica transdisciplinaridade da arquitetura e urbanismo, conforme corroboram os vestígios teóricos e históricos apresentados a seguir. 


\section{A transdisciplinaridade na história da teoria da arquitetura e urbanismo}

Em Vitrúvio (1914), a transdisciplinaridade já se fez presente em sua consagrada obra De Architectura, que inaugurou no séc. I a.C. uma tradição teórica mais racional sobre o poder construtivo humano. Em seus dez livros, o arquiteto utilizou-se de vários conhecimentos para abordar a construção do Espaço de um ponto de vista universal, como era próprio à cultura clássica. Ele se valeu tanto de conhecimentos distintos entre si aos dias de hoje, como a estética, a geografia, a mitologia e a astrologia, como também indicou a necessidade de uma formação plural ao arquiteto: segundo suas próprias palavras, o arquiteto deveria dominar saberes e técnicas como geometria, história, filosofia, música, medicina, direito... Por tal abrangência, e pela capacidade de costurar um entendimento racional em uma episteme universalista, talvez não seja à toa que essa é ainda hoje uma das obras mais emblemáticas da arquitetura.

Após Vitrúvio, na Idade Média, a transdisciplinaridade da arquitetura e urbanismo não chegou a ser evidenciada devido ao escasso desenvolvimento teórico da época, decorrente do domínio religioso e também do predomínio de um saber construído na prática. Mas vale citar que esse saber prático não é garantia da supressão de uma atuação comum entre diferentes conhecimentos, mas somente não são conhecidos documentos a esse respeito. Desse período, apenas fragmentos literários registrados por mestres construtores podem ser tidos como indícios da articulação entre saberes e práticas. Nas ilustrações do Álbum de Villard de Honnecourt (séc. XIII), por exemplo, percebe-se um interesse interdisciplinar que extrapola o espaço construído e busca inspiração na observação da natureza, das invenções mecânicas, das proporções do corpo, etc. Essa modalidade do saber desenvolvida na prática exerceu influências por longos séculos, tendo sido inclusive continuada por gênios da Renascença como Leonardo da Vinci.

Foi o Renascimento que retomou a transdisciplinaridade da arquitetura e urbanismo quando do enfraquecimento do domínio religioso medieval. Apesar de terem sido lançados aí os alicerces da epistemologia moderna, houve de início uma rica interação entre ciências e artes. Segundo o historiador Carlos Brandão, a racionalização e o humanismo renascentista foram retomados através de um processo que buscou superar o cosmos universalista clássico por um cosmos cultural moderno, e que, para o autor, equivaleria à própria "pré-história da transdisciplinaridade":

O legível e o visivel, a ideia e a forma material, o mundo do pensamento e o mundo construído, as humanidades e a Arquitetura compenetram-se de tal modo que fica impossivel distinguir onde termina um campo e começa o outro. Diluídas as fronteiras dos campos e disciplinas, estes passam a fecundarem-se reciprocamente, deixarem-se contaminar uns pelos outros e adquirirem novas formas geradas deste contágio. Contaminada pelas humanidades, a Arquitetura torna-se outra e é pensada em novas chaves. (BRANDÃO, 2005, p.5)

Especificamente no espaço construído, o transdisciplinar cosmos cultural renascentista foi evidenciado pelo De Re AEdificatoria (1443-1462) de Leon Battista Alberti. Nesse Tratado, como em Vitrúvio, arquitetura e cidade são consideradas como um todo integrado e ligado a diferentes campos do conhecimento e da práxis. Tal qualidade 
3 Publicado originalmente em 1737.

4 Publicado originalmente em 1674.

5 Publicado originalmente em 1867. também foi evidenciada pela formação de Alberti, que foi para a época um exemplo de pensador por dominar múltiplas artes - tendo inclusive escrito obras diversas como Tranquillità dell'Anima, De Amore, Della Famiglia, De Pictura, De Jure Tratactus e Ludi Mathematici -, e também por defender, assim como o fez Vitrúvio, uma formação plural para o arquiteto:

(...) se devêssemos assinalar uma arte, por sua natureza indispensável, e que conseguisse conciliar também a conveniência prática com o agrado e o decoro, a meu ver nessa categoria dever-se-ia incluir a arquitetura; (...) Chamarei de arquiteto aquele que com um método e um procedimento determinados e dignos de admiração tenha estudado o modo de projetar teoricamente e também realizar praticamente, mediante o deslocamento dos pesos e mediante a reunião e conjunção dos corpos, obras que se adaptem de uma forma harmônica às necessidades dos homens. Para que isso aconteça, ele precisa dominar os conhecimentos mais excelsos e adequados. Tal deverá ser então o arquiteto. (ALBERTI, 2012, p.29)

Após Alberti, possivelmente pela crescente predominância do método científico, o séc. XVI passou a expressar a tendência às especializações em lugar da integração entre saberes. Um processo epistemológico que se estendeu até o séc. $X X$, quando as crises contemporâneas passaram a demandar novas perspectivas para o conhecimento. Apesar disso, ainda se pode observar na modernidade indícios a respeito da transdisciplinaridade do espaço construído.

Vê-se em arquitetos barrocos como Francesco Borromini e Guarino Guarini uma apropriação científica paralela a interações transdisciplinares. Segundo o historiador inglês Anthony Blunt (1989), Borromini obteve de seu contemporâneo Galileu Galilei uma visão matemática e geométrica da natureza para o seu experiencialismo sensorial barroco. E em Guarini, o anseio científico se revela na similitude de seus escritos com trabalhos matemáticos coevos, como na comparação entre seu Architettura Civile ${ }^{3}$ e Cursus Mathematicus ${ }^{4}$ de Millet Dechales. Ademais, Guarini teve uma formação plural assim como Alberti, tendo também elaborado literaturas diversas como Placita Philosophica, Celestis Mathematica, etc.

Até aqui, a transdisciplinaridade na construção do Espaço se expressava de modo espontâneo: munidos do ideal construtivo relativo a cada época, arquitetos aparamentavam-se dos conhecimentos mais eficazes disponíveis. Mas a partir de então, embora sejam observadas outras articulações modernas entre saberes e práticas, a transdisciplinaridade parece ter-se mostrado cada vez mais como uma necessidade, uma carência por novos ideais conceptivos. E esse processo seria agravado ainda pela segmentação científica da arquitetura e do urbanismo como disciplinas autônomas interdependentes, principalmente a partir da Teoría General de la Urbanización ${ }^{5}$ do engenheiro espanhol Ildefons Cerdà. Inclusive, muitas das expressões transdisciplinares protomodernistas do Espaço, sucedâneas ao barroco, foram elaboradas por profissionais não arquitetos nem urbanistas. Entre os séc. XIX e XX o biólogo escocês Patrick Geddes concebeu a "Polística", uma proposta científica que tratava das origens da cidade, sua distribuição, estrutura, funcionamento e evolução; assim como posteriormente o arquiteto e historiador americano Lewis Munford, que tratou do urbanismo a partir de suas múltiplas dimensões históricas e culturais, fugindo a abordagens meramente técnicas (CHOAY, 1965). 
6 Publicado originalmente em 1971.

\footnotetext{
7 Publicado originalmente em 1977.

8 Publicado originalmente em 2002.
}

O protomodernismo parecia prenunciar aquilo que se apresentaria mais claramente ao final da era moderna com o Movimento Modernista, desde o seu auge até a sua queda e transição para o pós-modernismo. Com o Modernismo, a arquitetura e o urbanismo alcançaram suas máximas expressões técnico-científicas, de modo que a transdisciplinaridade desses campos foi relativizada por uma certeza generalizada na ciência. Um cenário que ficou notoriamente conhecido por uma rica produção teórica, como especialmente El Modulor de Le Corbusier, obra que trata do edifício e da cidade como máquinas. E muito embora o Movimento Modernista tenha logrado ricas contribuições para a construção do Espaço, principalmente em seus ideais estéticos e experienciais, Brandão aponta aí para uma inevitável perda da "arché", isto é, de uma ideia elementar e fundante do Espaço, devido a uma maior valorização tectônica:

Portanto, a modernidade (...) leva, no século XIX, à perda da arché. Não que a partir daí o que se tenha edificado não tenha importância. A originalidade e a vitalidade da arquitetura do século XX provam-nos o contrário, (...). Importa que, ao final do Rococó e do Barroco Tardio, a arquitetura, etimologicamente compreendida, deixa de ser produzida, pois não coloca mais a questão da origem, do fundamento, da arché a ser fenomenalizada, visível em seus edifícios. O tectônico absorve ou anula a arché. (BRANDÃO, 1999, p.227-228)

Parece ter sido na unidade da Ciência que o Modernismo tentou reencontrar a "arché" possivelmente perdida. Mas, como já se sabe, o declínio do Movimento Modernista na metade do séc. XX proporcionou as experiências e críticas pós-modernas e contemporâneas em suas múltiplas faces ideológicas, identitárias, sociais, ambientais... Faces estas que expuseram não só os limites do Modernismo, mas talvez da própria modernidade. Diante desse novo cenário, o Modernismo chegou a apresentar ainda uma expressão tardia que tentou conciliar a produção industrial e a ideologia da "máquina" com as novas compreensões mais heterogêneas que surgiam. É assim que se observa nesse momento, na construção do Espaço, uma retomada de proposições talvez ainda não transdisciplinares, mas interdisciplinares. É o caso de Richard Neutra, arquiteto austro-americano que concebeu a teoria "biorrealista" ao unir ideais modernistas a ideais da medicina de seu tempo, logrando tanto obras construídas quanto literaturas transversais como "Construindo com a Natureza" 6 .

À medida que o Modernismo declinava, a arquitetura e o urbanismo mais se aproximavam de outros campos do conhecimento. Ressurgiram abordagens em que o Espaço voltou a ser protagonista de seus aspectos conceptivos fundantes, junto à contribuição de diversas ciências e práticas como a biologia, a sociologia e a cibernética. Uma relação transdisciplinar em que se destacou a busca por modelos de desenvolvimento mais integrais do que progressistas, centrados na questão da Sustentabilidade, e apoiados na Informática e suas técnicas digitais de projeto e processamento de dados para um maior poder no cruzamento e modelagem de informações. O arquiteto Christopher Alexander é um exemplo dessa retomada transdisciplinar. Autor de obras como "A Linguagem dos Padrões" 7 e "A Natureza da Ordem"8, ele tem se dedicado há décadas a um entendimento racional, transdisciplinar e evolutivo do habitat. Inclusive, Choay tece comparações entre Alexander, Corbusier e Cerdà, evidenciando naquele uma ligação mais intensa com um pensamento pluriabrangente distanciado do Modernismo. 
9 Publicado originalmente em 2002.

10 Publicado originalmente em 1977.

11 Publicado originalmente em 1995.
Ao contrário de autores como Le Corbusier, ele [Cristopher Alexander] tomou cuidado de informar-se sobre as pesquisas contemporâneas em matéria de biologia. Vê-se assim dotado de um conhecimento muito mais elaborado que aquele que a ciência de sua época oferecia a Cerdà. Conhece a cibernética, é informado do andamento da biologia molecular e das contribuições que Ihe trouxe a linguística estrutural. Utiliza as noções de sistema (vivo), de crescimento, de controle e as transpõe para o objeto urbano cujos princípios de 'desenvolvimento orgânico', de crescimento fragmentado' ele anuncia. (CHOAY, 2010, p.295)

E além de investigações objetivas como as de Alexander, observa-se ainda na retomada contemporânea da transdisciplinaridade expressões mais paradigmáticas do que projetivas. Expressões que evidenciam uma rede de conhecimentos profícuos para a concepção do Espaço e debruçam-se em críticas epistemológicas sobre preceitos modernos, envolvendo-se aí com as ciências contemporâneas do sistemismo e da complexidade e defendendo a necessidade de horizontes transdisciplinares. É o caso de Charles Jencks, arquiteto que teria sido responsável por cunhar o termo "pósmodernismo" e que escreveu obras como The New Paradigm in Architecture: The Language of Post-Modernism ${ }^{9}$, revisão do famoso The Language of Post-Modern Architecture ${ }^{10}$, e The Architecture of The Jumping Universe ${ }^{11}$, no qual aborda temas peculiares como emergência e cosmogenia.

Por fim, é no sentido dessa trajetória de objetivação e disciplinarização epistêmica, mas de recente reampliação teórico-prática, de uma "retransdisciplinarização" mesmo, que se defende aqui a transdisciplinaridade como modo de agir e de pensar inerente à produção do Espaço. Um processo a que o arquiteto inglês Anthony Vidler parece ter propiciado visibilidade ao tomar das artes já ao início do séc. XXI o termo "Campo Ampliado", cunhado originalmente em 1979 por Rosalind Krauss (1984). Vidler esclarece o uso do termo ao citar as interações recentes que a arquitetura e o urbanismo passaram a realizar com várias outras disciplinas:

Depois de várias décadas de autonomia autoimposta, a arquitetura ingressou há pouco em um campo bastante ampliado. (...) a arquitetura - como a escultura algumas décadas antes - encontrou nova inspiração formal e programática num conjunto de disciplinas e tecnologias que vão do paisagismo à animação digital. (...) subjacente à nova experimentação formal, existe uma série de tentativas de reconstruir os fundamentos da disciplina, não tanto em termos singulares, mas através de conceitos mais amplos que reconheçam o campo ampliado (...). (VIDLER, 2013, p.247)

É no âmbito do "Campo Ampliado" que se dá a aproximação da arquitetura e urbanismo com a ideia de Autopoiese, havendo aí uma rica vazão à transdisciplinaridade junto às várias áreas do conhecimento abrigadas pelo conceito, e com as Ciências da Complexidade em geral, devido a outras teorias como a auto-organização e a ideia de sistema aberto. E é com base nisso que reconhecemos uma apropriação unilateral do conceito de Autopoiese por Patrik Schumacher. Objetivamente, a suspeita é a de que Schumacher, ao não absorver a transdisciplinaridade que é própria ao conceito e também é defendida aqui como inata à arquitetura e urbanismo, poderia estar incorrendo em equívocos teóricos. E especialmente, por Schumacher defender a sua obra, The Autopoiesis of Architecture, como uma literatura autodescritiva de vanguarda contemporânea. 
É Françoise Choay quem permite vislumbrar a validade dessa suspeita. Em suas teorias, a autora relata com maior acuro o processo que aqui denominamos "retransdisciplinarização", ao falar diretamente de uma "objetivação teórico-espacial" ocorrida no crescente envolvimento da arquitetura e urbanismo com a Ciência na construção de suas disciplinas modernas. Uma objetivação que pode ser considerada como contributo das crises que se evidenciaram sobre as cidades entre os séculos XIX e XX, e em função da qual a retomada da transdisciplinaridade parece ser condição sine qua non para um entendimento contemporâneo do Espaço e a abrangência que ele requer. Daí o erro que reconhecemos na obra de Schumacher e que procuramos demonstrar a seguir.

\section{Françoise Choay e as teorias da arquitetura e urbanismo}

Em "O Urbanismo", o objetivo de Choay foi "captar o sentido real do urbanismo propriamente dito, sob suas diversas formulações e fórmulas, e situar os problemas atuais do planejamento urbano" (CHOAY, 2015. p.3). Ao longo dessa obra, a autora perpassa uma série de concepções urbanísticas dos séc. XIX e XX, e avança para mais antigamente sobre concepções que denomina "pré-urbanismo". Choay estuda autores que, dotados ou não do título de urbanista ou arquiteto, contribuíram para o desenvolvimento das cidades. Ela defende que o desenvolvimento da ciência do urbanismo teria se "colocado bem antes da criação da disciplina, quando a sociedade industrial começava a tomar consciência de si e a questionar suas realizações" (ibid. loc. sit.).

Choay analisa em seu livro diversas concepções teórico-espaciais que se combinam entre diferentes categorias, desde autores como Robert Owen e William Morris a Karl Marx, Jane Jacobs, Kevin Lynch, etc. Mas o que Choay considera da leitura desses autores é a constatação de que o urbanismo não se configura como uma ciência, muito embora aportes científicos tenham sido sempre associados a esse campo do conhecimento. Segundo ela:

Apesar das pretensões dos teóricos, o planejamento das cidades não é o objeto de uma ciência rigorosa. Muito mais: a própria ideia de um urbanismo científico é um dos mitos da sociedade industrial. Na raiz de qualquer proposta de planejamento, por trás das racionalizações ou do conhecimento que pretendem fundá-la em verdade, escondem-se tendências e sistemas de valores. (CHOAY, 2015, p.49-50)

Choay (ibid. p.49-56) faz outras declarações contundentes: apesar de o séc. XX ter se deparado com uma crise do urbanismo, restara uma "ilusão ingênua e persistente de uma abordagem científica". Tal situação teria levado ao desconhecimento da própria natureza da cidade, pois a linguagem urbana tradicional, desenvolvida no convívio de seus múltiplos atores, teria sido alterada por grupos de decisão especializados que, com ciência e técnica, a teriam transformado em uma "língua morta", substituída por "linguagens logotécnicas". A autora atenta assim para uma supressão da dialética do espaço urbano, no qual os cidadãos comuns já não encontram voz e participação, e atenta ao seu resgate como essencial para a concepção de novos ideais urbanísticos.

Posteriormente em "A Regra e O Modelo", Choay parte das constatações realizadas em "O Urbanismo" para investigar a natureza dos escritos da arquitetura e urbanismo. 
12 "[1] É um livro, apresentado como uma totalidade organizada. [2] Este livro é assinado por um autor que Ihe reivindica a paternidade e escreve na primeira pessoa. [3] Seu desenvolvimento é autônomo. Não pretende subordinar-se a nenhuma disciplina ou tradição. [4] Tem por objeto um método de concepção, a elaboração de princípios universais e de regras generativas que permitam a criação, não a transmissão de preceitos ou de receita. [5] Esses princípios e essas regras se destinam a engendrar e a cobrir o campo total do construir, desde a casa à cidade, da construção à arquitetura." (CHOAY, 1980. p.16)

13 Publicado originalmente em 1516.

14 "[1] uma utopia é um livro assinado; [2] nela um indivíduo se exprime na primeira pessoa do singular, o próprio autor elou seu porta-voz, visitante ou testemunha da utopia; [3] apresenta-se sob a forma de uma narrativa na qual se insere, no presente do indicativo, a descrição de uma sociedade-modelo; [4] essa sociedade-modelo opõe-se a uma sociedade histórica real, cuja crítica é indissociável da descrição-elaboração da primeira; [5] a sociedade-modelo tem como suporte 'um espaço-modelo que é sua parte integrante e necessária'; [6] a sociedade-modelo está situada fora do nosso sistema de coordenadas espácio-temporais (sic), alhures; [7] ela escapa à influência do tempo e das mudanças." (CHOAY, 1980, p.36-37)
Ela divide a teoria desse campo em dois grandes grupos: "Escritos Realizadores", concebidos para o espaço construído, e "Escritos Comentadores", de influência indireta na realização do Espaço. Dentre os primeiros, a autora apresenta ainda o subgrupo "Escritos Instauradores", criados já no âmbito de uma teoria da arquitetura e urbanismo como campo autônomo moderno.

As atenções de Choay recaem majoritariamente sobre os Escritos Instauradores. Segundo ela, houve até hoje três modalidades desse tipo literário: Tratados, ou a "regra" a que se refere o livro; Utopias, o "modelo"; e Teorias Urbanísticas do séc. $X X$. Para cada uma delas, Choay elenca características essenciais presentes em obras a que ela identifica como principais. E na ausência de alguma dessas características, outras obras não poderiam ser classificadas como pertencentes à mesma modalidade, mas apenas variações de Tratados, Utopias ou Teorias.

Quanto aos Tratados, Choay toma por obra prima o De Re AEdificatoria de Alberti, e elenca para ele cinco características distintivas ${ }^{12}$. Segundo a autora, nenhuma outra obra teórica teria apresentado até então todas essas características, o que torna originária a obra de Alberti. Mesmo o De Architectura de Vitrúvio teria apenas iniciado o processo de racionalização dos Tratados. E é com o modelo do Tratado, principalmente, que a autora atenta para o início da objetivação teóricoespacial. Essa literatura teria se desenvolvido a partir de uma maior racionalização do espaço construído, sendo influenciada por estudos de sítios arqueológicos clássicos. Era o reflexo do desejo renascentista de se apropriar da herança clássica sob a ótica de um humanismo racional e científico. O próprio Alberti, no início de sua carreira, estudou e desenhou a cidade de Roma em sua obra Descriptio Urbis Romae (1432-34).

Quanto às Utopias, a referência maior está na obra homônima Utopia ${ }^{13}$ de Thomas Morus, na qual Choay reconhece sete características distintivas ${ }^{14}$. Mas, principalmente, Choay entende esse tipo literário como oposto aos Tratados: enquanto estes buscaram a máxima racionalização, as Utopias voltaram-se a especulações sobre o espaço construído, tendo logrado obras não eruditas, mas acessíveis à população e úteis para a disseminação de críticas à cidade industrial. É assim que, em Utopia e outras obras a que esta teria influenciado, são apresentados relatos romantizados sobre lugares fantasiosos, a partir dos quais são desenvolvidas descrições sociais e espaciais que esboçaram críticas às realidades urbanas de suas épocas. Um novo patamar da objetivação teórico-espacial que se atenuava na racionalização e endossava-se a partir das idealizações espaciais contidas em suas literaturas.

No terceiro tipo literário, as Teorias do Urbanismo, Choay apresenta um relevante diferencial em relação aos tipos anteriores. Segundo ela, este não seria um tipo original, mas uma mescla entre o Tratado e a Utopia, entre a normatização e a idealização. Essa hibridização teria se tornado possível pela crescente crença no saber científico, que, cada vez mais hegemônico, tido como reflexo mesmo da realidade, teria possibilitado a idealização de concepções urbanas a partir de racionalizações científicas. Mas racionalizações que, para Choay, seriam cientificistas por estarem sempre acompanhadas de tendência de valores. Por exemplo, Choay diz sobre a Teoría General de la Urbanización de Cerdà que: 
A 'Teoría' não satisfaz a uma série de exigências atualmente características de uma teoria científica: a capacidade explicativa, a capacidade de previsão, a transitividade e sobretudo a refutabilidade. Sua margem de adesão aos fatos é limitada. (...) Enfim, a 'teoria' de Cerdà é apresentada como uma verdade fixa e imutável, em termos que podemos imputar a um cientificismo, mas que dependem bem mais de um enfoque utopista. (CHOAY, 2010, p.277)

Assim, as Teorias do Urbanismo configurariam um último estágio da objetivação teóricoespacial a que remete Choay. Com elas, a racionalização tratadística e a idealização utopística teriam se fundido em uma só e mesma especulação cientificista, que teria impulsionado o desenvolvimento urbano no final do séc. XIX e ao longo do séc. XX.

\section{Autopoiese e transdisciplinaridade}

Quanto à Autopoiese, o valor transdisciplinar desse conceito está não só em sua abrangência científica, mas na disposição de seus criadores, Maturana e Varela, em buscar conceber com a Teoria de Santiago (na qual está inserido o conceito) um entendimento imbrincado entre o saber e o fazer humano. De modo suscinto, a ideia de Autopoiese se refere a uma suposta qualidade basilar aos seres/sistemas vivos: a capacidade de se autorreconstituir, de se conservar entre os estímulos do ambiente. Para explanar em pormenores sobre o conceito, a recente dissertação de mestrado intitulada "Arquitetura, Urbanismo e Autopoiese: conceitos, contextos e críticas de um complexo campo ampliado" (CARMO, 2019) sugere entendê-lo a partir de quatro aspectos básicos: organização, cognição, interação e ética. Isto porque, grosso modo, o conceito abrange desde a dinâmica da organização biológica da vida até questões pertinentes à percepção, à interação entre indivíduos e a comportamentos éticos. Em outras palavras, a Autopoiese correlaciona objetividades práticas do fazer com subjetividades do pensar, o que possibilitou a Maturana e Varela (1995) sugerirem, por exemplo, bases biológicas a questões sociocognitivas como o respeito e a paz. Além disso, o conceito de Autopoiese tem se ampliado ainda mais pela apropriação de outros autores como Humberto Mariotti (1999), que tece considerações entre fenomenologias biológicas e sociais, e Fritjof Capra (1996), que o resume como "o padrão da vida".

\section{Autopoiese na arquitetura}

Face à abrangência da Autopoiese à moderna objetivação teórico-espacial comentada por Choay, atenta-se aqui aos equívocos da obra de Schumacher. Também em sua dissertação, Carmo (2019) empreende uma análise do The Autopoiesis of Architecture. Nessa análise, ele identifica significativas incongruências, inconsistências e incompletudes na apropriação da ideia de Autopoiese: especificamente, Schumacher não observa a condição transdisciplinar do conceito e nem se apropria dele em sua integralidade, mas apenas da qualidade de "autonomia" ligada ao seu aspecto organizativo. Isso pode ter sido favorecido pelo fato de que Schumacher não adentra no campo das demais Teorias da Complexidade, que permitem um entendimento mais amplo e claro da Autopoiese. E no mais, ao também comparar a obra de Schumacher com as categorias literárias de Choay, Carmo observa nela aspectos tratadistas e utopistas, do que conclui que seus escritos se comportam como as Teorias Urbanísticas dos séc. XIX e XX. Um anacronismo, portanto; e um idêntico cientificismo, já que Schumacher, 
tal qual os urbanistas daquele período, apoia-se em um conceito científico de seu tempo, mas buscando conceber uma literatura conduzida majoritariamente por seu sistema de valores, concentrados neste caso no Parametricismo.

\section{O espaço como expressão transdisciplinar em Norberg-Schulz}

O esforço teórico aqui apresentado nos aproxima dos modos de refletir de variadas disciplinas a respeito de um mesmo tema - no nosso caso, a arquitetura e urbanismo. Morin (2011) diz que o pensamento complexo tem sua base crítica naquilo que ele denomina de pensamento redutor, quando da adoção de uma visão unidimensional, e adota a "metáfora do mutilador" para referir-se aos pensamentos que se fecham ao diálogo e às perspectivas que podem surgir do encontro entre campos do conhecimento. Objetivamente, a complexidade trata de considerar aspectos como "incerteza", "imaginação" e "intuição", estruturas de pensamento que durante os tempos iluministas que persistiram até o Modernismo foram amortecidos na Epistemologia. É assim que hoje são reconhecidas construções teóricas e metodológicas as mais diversas, rompendo-se o espírito redutor que se abrigou por séculos na Academia, sob princípios apriorísticos que não reconheciam a complexidade na construção do conhecimento. Um cenário que pode ser exemplificado pela antítese entre a figura do Enciclopedista, comum ao lluminismo, e a antiga figura do Polímata. Este não apenas acumula saberes, mas busca encontrar relações entre eles. Segundo Burke (2020), o reconhecimento histórico dos polímatas é uma reação à especialização. Ele se refere a grandes pensadores como o já citado Leonardo da Vinci, lamentando que essa figura, que abarca diversas estruturas de conhecimento, é obsoleta, embora na atualidade não se possa prescindir do pensamento sistêmico.

Vislumbrar a importância do Campo Ampliado para a matéria primeira da arquitetura e urbanismo - o Espaço - também pode ser um modo de nos contrapormos à redução teórica. Se tomarmos a classificação de Giedion (2004) de três tipos de espaço - aberto, fechado e aberto-fechado - e considerarmos algumas das observações de Norberg-Schulz (1999), podemos entender como é arriscado construir conceitos fechados. Giedion é um dos pensadores modernos que buscaram relações interdisciplinares. Em seu livro "Espaço, Tempo e Arquitetura" (1941), ele constrói relações entre arquitetura e outras atividades humanas, artes e ciências. Sua concepção de espaço aberto-fechado, ele a relaciona à espacialidade contida nas esculturas do artista suíço Giacometti (vide "A praça"). Contudo, ainda assim, Norberg-Schulz no livro "Arquitetura Ocidental" (1973), com uma compreensão fenomenológica, constrói uma crítica a Giedion sobre a complexidade do Espaço. E note-se que a fenomenologia, que é muitas vezes tida como busca de totalidade, nos parece ser também uma busca de integração entre saberes e experiência.

Referindo-se à relação que as pirâmides egípcias estabelecem com o espaço, Giedion (2004) dizia que esses seriam espaços abertos, sem busca de interação com a natureza. Para ele, um exemplo de espaço fechado seria a cúpula romana, e de espaço abertofechado, o espaço modernista, ao mesmo tempo "dentro e fora", em função da transparência na relação interior-exterior. Já Norberg-Schulz (1999), observando aquele mesmo espaço egípcio, diz que as pirâmides egípcias estão localizadas no Baixo Egito, onde a cordilheira do Alto Egito termina. Ele entende que uma grande relação paisagística e simbólica acontece ali, porque as pirâmides mantêm o espírito 
do lugar ao assumirem o papel de continuadoras das montanhas. Ele foi buscar na geografia, na paisagem, na filosofia, assim como na cultura daquele povo antigo, um entendimento para o significado do Espaço na reconstituição da paisagem.

Assim também, enquanto há historiadores que sequer reconhecem a existência do período Maneirista, dividindo aquele tempo em Renascimento e Barroco, novamente Norberg-Schulz reconhece no Maneirismo um período de reflexão crítica em relação à Era de Certezas do Renascimento. Em sua percepção sobre o Espaço maneirista, ele diz que a arquitetura daquele período contradiz o conceito renascentista de espaço homogêneo: ao invés de uma ordem estática, isotrópica, há "uma sucessão espacial dinâmica, diferenciada. Dentro da extensão geral do espaço, se determinaram lugares, ambientes qualitativamente diferentes, em interação. (...) [O espaço] passou a ser objeto de experiência emocional" (ibid. p.148).

A obra Arquitectura Occidenta/ de Norberg-Schulz algumas vezes é lida apenas como um livro de história da arquitetura. Mas, conhecendo-se o seu livro-referência, Existence, Space \& Architecture (1971), onde sua Teoria do Espaço Existencial é explicitada, facilmente percebe-se que Arquitectura Occidental é, em verdade, uma aplicação da sua Teoria a vários períodos da História. Ou seja, trata-se de um livro teórico e metodológico, não apenas histórico, e é com este entendimento que adotamos esta referência neste artigo, onde paisagem, assentamento, percursos, significados, símbolos e tectônica compõem o sistema que integra a Teoria do Espaço Existencial.

Poderíamos continuar tecendo mais referências, a exemplo da evolução do entendimento de sítio histórico que mudou drasticamente desde a Carta de Veneza nos últimos anos 70, quando trouxe a condição de lugar com mais efetividade para a Teoria da Conservação. Desde então, se naquele período se incorporou na arquitetura e urbanismo a importância do entorno dos monumentos, hoje são incorporados costumes, pessoas, refazendo-se inclusive, a partir do espaço edificado, o entendimento de memória como conceito e como diretriz. São exemplos que trazem a complexidade, mas principalmente a transdisciplinaridade, para a vida cotidiana. Segundo a Fenomenologia, enfim, somos seres espaciais, o que significa dizer que é impensável considerar o Espaço sem o ser humano. E isso faz com que o Espaço, porquanto construção eminentemente humana, assuma a possibilidade de ser, naturalmente, um campo ampliado.

\section{Resultados}

A crítica sobre a apropriação do conceito de Autopoiese por Schumacher faz compreender a atenção que parece devida a arquitetos e urbanistas quanto à transdisciplinaridade do espaço. A obra The Autopoiesis of Architecture, bem como a presença em seu título de um termo científico pouco conhecido, mas abrangente, é suscetível de erguer fascínios que só uma atenção transdisciplinar pode desmistificar. Se pela teoria da arquitetura e urbanismo Choay possibilita classificar essa obra como anacrônica, misto de normatização e especulação mais moderno que contemporâneo, é também pelo entendimento mais aprofundado de Autopoiese que se pode constatar a cientifização que ocorre em Schumacher, tal qual as Teorias Urbanas Modernas. Os fascínios do autor ainda parecem ser alimentados pelo foco no Parametricismo, fazendo com que ocorra, assim como Brandão sugere sobre a modernidade, uma valorização da tectônica acompanhada da perda da arché. 
Essa crítica encontra igual consonância na objetivação teórico-espacial apontada por Choay em relação à modernidade. Objetivação que, como relatado, suprimira o entendimento da natureza da cidade ao sobrepor a linguagem técnico-científica à linguagem tradicional do espaço urbano. Mas linguagem que precisaria ser recuperada para que possamos lidar com as com problemáticas da moderna cidade-máquina que ainda resiste na contemporaneidade.

Perguntamo-nos se não seria essa dialética uma menção à transdisciplinaridade, reconhecendo-se nela uma interação entre os diferentes atores e pensadores do espaço urbano; uma interação entre aspectos de todas as ordens, desde as ciências às artes, que, como observamos, parecem estar imanentemente ligadas ao Espaço. É assim que defendemos a transdisciplinaridade como natural à construção do espaço, corroborada igualmente pelos registros históricos e excertos da Estética aqui apresentados.

Importa ressaltar que o intuito dessa defesa, por parte dos autores, é destacar a transversalidade disciplinar, sob o entendimento de que isso se constitui quase que em um método de se pesquisar e de construir conhecimento. As interações entre saberes distintos, o reconhecimento do Campo Ampliado - que no caso aqui é fomentado pelas Ciências da Complexidade e pelo conceito de Autopoiese- permitem descobertas que, tal como o "escavar" na arqueologia, e sob o impulso das informações e intuições que se apresentam, podem revelar novos entendimentos e pôr em questão conhecimentos sedimentados. Daí que esse tipo de postura parece ser tanto exercício extremado da consciência quanto da experiência; exercício transdisciplinar que, como vimos, não se opõe à autonomia dos campos do saber e do fazer, e que, finalmente, parece se colocar como imprescindível à contemporaneidade.

\section{Referências bibliográficas}

ALBERTI, Leon Battista. Da Arte de Construir, tratado de arquitetura e urbanismo. Tradução Sergio Romanelli. São Paulo: Hedra, 2012. 458 p.

BLUNT, Anthony Frederick. Borromini. Cambridge: Havard University Press, 1989. 240 p.

BRANDÃO, Carlos Antônio Leite. A Formação do Homem Moderno Vista Através da Arquitetura. 2. ed. Belo Horizonte: Ed. UFMG, 1999. 240 p.

A Pré História da Transdisciplinaridade: a construção do saber em Alberti e Leonardo. In: Colóquio CBHA, 24., 2004, Belo Horizonte. Anais [...]. Salvador: Comitê Brasileiro de História da Arte, 2005. Disponível em: <http://www.cbha.art.br/coloquios/2004/anais/ anais2004.html>. Acesso em: 07 out. 2021.

BURKE, Peter. O Polímata, uma história cultural de Leonardo da Vinci a Susan Sontag. Tradução Renato Prelorentzou. São Paulo: UNESP, 2020. 512 p.

CAPRA, Fritjof. A Teia da Vida: uma nova compreensão científica dos sistemas vivos. Tradução Newton Roberval. São Paulo: Editora Cultrix, 1996. 256 p.

CARMO, Alison Jorge Alves do. Arquitetura, Urbanismo e Autopoiese: conceitos, contextos e críticas de um complexo campo ampliado. Orientadora: Maria de Jesus de Britto Leite. 2019. 228f. Dissertação (Mestrado em Desenvolvimento Urbano) - Universidade Federal de Pernambuco, Recife, 2019.

CHOAY, Françoise. A Regra e o Modelo: sobre a teoria da arquitetura e urbanismo. Tradução Geraldo Gerson de Souza. 2. ed. São Paulo: Perspectiva, 2010. 333 p. 
CHOAY, Françoise. O Urbanismo: utopias e realidades, uma antologia. Tradução Dafne Nascimento Rodrigues. 2. ed. São Paulo: Perspectiva, 2015. 350 p.

COUTINHO, Evaldo. O Espaço da Arquitetura. Recife: Universidade Federal de Pernambuco, 1970.

GIEDION, Sigfried. Espaço, Tempo e Arquitetura, o desenvolvimento de uma nova tradição. Tradução Alvamar Lamparelli. São Paulo: Martins Fontes, 2004. 972 p.

GRILLO, Antonio Carlos Dutra. De/Para Arquitetura: a ciência da complexidade. Cadernos de Arquitetura e Urbanismo, Belo Horizonte, v. 15, n. 16, p.128-129, mar. 2008.

HONNERCOURT, Villard de. Album de dessins et croquis. Bibliothèque Nationale de France. Département des Manuscrits. XIII siècle. Disponível em: <https://www.masoniclib.com/ images/images0/03892,6724117.pdf>. Acesso em: 17 mar. 2021.

Krauss, Rosalind. A Escultura no Campo Ampliado [Sculpture in the Expanded Field]. Originalmente publicado em October, nº 18, Massachusett: MIT Press, 1979. Também publicado em The AntiAesthetic: Essays on PostModern Culture, Washington: Bay Press, 1984. Tradução publicada em Gávea, revista do Curso de Especialização em História da Arte e Arquitetura no Brasil, nº 01, PUC-Rio, 1984.

LACERDA, Norma. O Campo do Planejamento Urbano e Regional: da multidisciplinaridade à transdisciplinaridade. Revista Brasileira de Estudos Urbanos e Regionais, v. 15, n. 1, p. 77-93, maio 2013. Disponível em: <https://rbeur.anpur.org.br/rbeur/article/view/4171>. Acesso em: 07 out. 2021

MARIOTTI, Humberto. Autopoiese, Cultura e Sociedade. 1999. Disponível em: <http://www. dbm.ufpb.br/ marques/Artigos/Autopoiese.pdf>. Acesso em: 17 mar. 2021.

MATURANA, Humberto R.; VARELA, Francisco J. A Árvore do Conhecimento: as bases biológicas do entendimento humano. Tradução Jonas Pereira dos Santos. Campinas: Editora Psy II, 1995. 281 p.

MORIN, Edgar. Introdução ao Pensamento Complexo. Tradução Eliane Lisboa. 4. ed. Porto Alegre: Sulina, 2011. 120 p.

NORBERG-SCHULZ, Christian. Arquitectura Occidental. Barcelona: G. Gili, 1999. 240 p.

Existence, Space \& Architecture. New York: Praeger, 1971. 120 p.

RAMADIER, Thierry. Transdisciplinarity and its challenges: the case of urban studies. Futures, v. 36, n. 4, p.423-439, 16 jan. 2004. Disponível em: < https://www.sciencedirect.com/ science/article/abs/pii/S0016328703001927>. Acesso em: 07 out. 2021.

SANTOS, Boa Ventura de Sousa. Um Discurso Sobre as Ciências. 5. ed. São Paulo: Cortez, 2008. 92p.

SCHUMACHER, Patrik. The Autopoiesis of Architecture: A New Framework for Architecture. Londres: John Wiley \& Sons, 2011. v. I. 461 p.

The Autopoiesis of Architecture: A New Agenda for Architecture. Londres: John Wiley \& Sons, 2012. v. II. 773 p.

VIDLER, Anthony. O Campo Ampliado da Arquitetura. In: KRISTA SYKES, A. (org). O Campo Ampliado da Arquitetura: Antologia Teórica 1993-2009. Tradução Denise Bottmann. São Paulo: Cosac Naify, 2013. p.242-251.

VITRUVIUS. The Ten Books on Architecture. Translated by Morris Hick Morgan. London: Humphrey Milford Oxford University Press, 1914. 